\title{
Research Paper: The Psychometric Properties of the Persian Version of Dysmorphic Concern Questionnaire
}

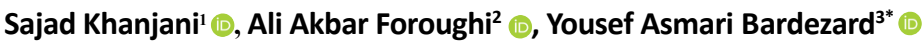

1. Department of Clinical Psychology, School of Behavioral Sciences and Mental Health, Iran University of Medical Sciences, Tehran, Iran

2. Department of Psychology, Kermanshah University of Medical Sciences, Kermanshah, Iran.

3. Department of Clinical Psychology, University of Social Welfare and Rehabilitation Sciences, Tehran, Iran.

\begin{tabular}{l|l}
\hline $\begin{array}{c}\text { Use your device to scan } \\
\text { and read the article online }\end{array}$ \\
morphic Concern Questionnaire. Journal of Practice in Clinical Psychology, 7(4), 263-270. http://dx.doi.org/10.32598/jpcp.7.4.263
\end{tabular}

\section{(c) (1) (9)}

Article info:

Received: 26 Apr 2019

Accepted: 10 Aug 2019

Available Online: 01 Oct 2019

Keywords:

Dysmorphic concern questionnaire, Confirmatory factor analysis, Validity, Reliability

\section{ABSTRACT}

Objective: The Dysmorphic Concern Questionnaire (DCQ) is a widely used screening instrument assessing dysmorphic concerns ranging from a mild to an excessive level. In Iran, there is no brief and valid questionnaire for the assessment of body dysmorphic disorder.

Methods: To investigate the psychometric properties of this scale, 210 university students (103 males and 107 females) were selected by convenience sampling method. The study participants were requested to complete the DCQ, scales of external shame, self-compassion, negative affect, and perfectionism. LISREL and SPSS were used for analyzing the obtained data. Confirmatory Factor Analysis (CFA), correlation coefficient, and Cronbach's alpha coefficient were calculated, as well.

Results: The one-factor structure of DCQ was supported by the results of CFA in an Iranian sample $\left(\mathrm{X}^{2} / \mathrm{df}=2 / 12\right.$, RMSEA $\left.=0.07, \mathrm{NFI}=0.94, \mathrm{CFI}=0.97\right)$. Dysmorphic concern was positively and significantly correlated with external shame scale $(0.38)$, perfectionism $(0.22)$, and negative affect $(0.22)$; however, they were negatively and significantly correlated with self-compassion (0.16). Cronbach's alpha coefficient was obtained equal to 0.78 in this respect.

Conclusion: DCQ demonstrated acceptable psychometric properties in university student populations. This scale has appropriate psychometric properties for research and clinical practice.

\footnotetext{
* Corresponding Author:

Yousef Asmari Bardezard, PhD. Student

Address: Department of Clinical Psychology, University of social welfare and Rehabilitation sciences, Tehran, Iran.

Tel: +98 (910) 4974603

E-mail: asmariyousef@yahoo.com
} 


\section{Highlights}

- Persian version of DCQ can be used as a useful tool to measure dysmorphic concerns in Iranian population.

- The internal consistency of the items in the Persian version of DCQ had acceptable Cronbach's alpha coefficient value $(\alpha=0.78)$.

- Dysmorphic concern was positively and significantly correlated with external shame scale, perfectionism, and negative affect.

- Dysmorphic concern negatively and significantly correlated with self-compassion.

\section{Plain Language Summary}

Dysmorphic concerns are defined as excessive preoccupations with a slight or perceived defect in physical appearance. Many studies have suggested that a higher rate of negative affect is associated with body image dissatisfaction. Some instruments have been used to screen body dysmorphic concern including the Dysmorphic Concern Questionnaire (DCQ). It is a self-report scale with 7 items based on a 4-point scale measuring concerns about physical appearance. The present study aimed at examining the psychometric properties of the DCQ among Iranian samples. To investigate the psychometric properties of this scale, 210 university students were selected by a convenience sampling method. This questionnaire had high internal consistency and had good divergence and convergence validity. The results suggested acceptable psychometric properties of this tool in university student population in Iran. This scale has appropriate psychometric properties to be used for research and clinical practice.

\section{Introduction}

ysmorphic concerns are defined as ex-

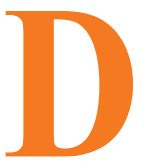
cessive preoccupations with a slight or perceived defect in physical appearance (Beilharz et al., 2019). Some concerns are specific (e.g. balding, large nose, acne, \& skin tone), while others are vague or no more than a general perception of ugliness. However, complaints of dissatisfaction with body shape and size that are a function of eating disorders are exclusionary criteria for Body Dysmorphic Disorder (BDD) (Association, 2013).

They are a symptom of BDD and may indicate BDD proneness or even a relevant subclinical or clinical diagnosis (Gieler et al., 2016; Senín-Calderón et al., 2017). In contrast to reasonable appearance concerns, preoccupations in BDD are experienced as intrusive and are difficult to resist and hard to control (Phillips, McElroy, Keck, Pope, \& Hudson, 1993).

In these settings, prevalence rates of dysmorphic concerns are reasonably high, ranging from 6.9 to $17.2 \%$ (Dey et al., 2015; Ritter et al., 2016). Philips reported that $76.4 \%$ of 398 BDD patients requested cosmetic surgeries and $66 \%$ underwent the surgery. However, the surgery was not effective in relieving the BDD symptoms (Phillips, Grant, Siniscalchi, \& Albertini, 2005). The prevalence of this disorder was reported to be higher in some groups, e.g. students (Grant, Lust, \& Chamberlain, 2019; Singh \& Veale, 2019). The prevalence of BDD in American and Turkish students were 4\% and 4.8\%, respectively (Ahamed, et al., 2016; Koran, Abujaoude, Large, \& Serpe, 2008). Many studies have suggested that a higher rate of negative affect is associated with body image dissatisfaction (Annesi \& Gorjala, 2010; Lattimore \& Hutchinson, 2010) and body image distortion (Farrell, Lee, \& Shafran, 2005; Taylor \& Cooper, 1992). Dysmorphic people often experience self-shame (Phillips, Siniscalchi, \& McElroy, 2004). External shame and self-compassion are related to body image dissatisfaction and eating disorders in the general population (Ferreira, Pinto-Gouveia, \& Duarte, 2013). Wasylkiw, MacKinnon, \& MacLellan, 2012. argued that graduated students with higher scores in selfcompassion were less concerned about their body image after controlling self-esteem (Wasylkiw, MacKinnon, \& MacLellan, 2012). Perfectionism was positively correlated with DCQ scores after controlling general pathology (Hanstock \& O'Mahony, 2002).

Instruments have been used to screen body dysmorphic concern, as the Body Dysmorphic Disorder Questionnaire; its dermatology version is a modified version of the Body Dysmorphic Disorder Questionnaire 
(BDDQ) (Phillips, Kim, \& Hudson, 1995). Additionally, the DCQ is a practical, seven-item questionnaire, which was developed and validated by Oosthuizen for the psychiatric setting (Murphy, 1973).

The questionnaire was designed to assess concerns about dysmorphia as a symptom and without the need for the diagnosis of BDD. The DCQ is a self-report scale in which the respondents rate their concerns about physical appearance based on a four-point scale. The patients were screened by BDD diagnostic scale for dysmorphic disorder or skin diseases (22 patients with BDD, 22 patients with skin diseases, and 21 patients with mild skin diseases). The patients with BDD acquired significantly higher scores in DCQ, compared to the controls. Cutting score of 11 in DCQ resulted in a more precise classification, where $100 \%$ of patients had BDD, $100 \%$ had mild side effects, and 59\% demonstrated dysmorphic side effects. The authors stated that cutting score of 14 delivers the most appropriate specificity and sensitivity because it provides an accurate classification of $72 \%$ of BDD patients and $90.7 \%$ of non-BDD patients (Stangier, Janich, Adam-Schwebe, Berger, \& Wolter, 2003).

DCQ is a concise and economical instrument, i.e., considered for clinical use as well as epidemiological studies in large samples (Liao et al., 2010; Mancuso, Knoesen, \& Castle, 2010). However, DCQ was only validated in clinical settings (Jorgensen, Castle, Roberts, \& Groth-Marnat, 2001; Stangier et al., 2003). Iran is among the pioneering countries in the field of plastic and cosmetic surgery. Moreover, BDD prevalence is increasing in some groups (e.g. students). Thus, it is essential to design a standardized short-term questionnaire to assess, screen, and study BDD in the Iranian population. Therefore, the present study aimed to assess the factor structure and psychometric features of DCQ.

\section{Methods}

This was a cross-sectional descriptive study. The statistical population of the study consisted of all Bachelor's, Masters and $\mathrm{PhD}$. students of Shahid Beheshti University of Medical Sciences. The target population was healthy people screened for body dysmorphic concerns. Klein believed that 10 or 20 samples are needed for each variable in Exploratory Factor Analysis (EFA); however, the minimum sample size of 200 also suffices (Kline, 2015). The study sample consisted of 210 students (103 boys and 107 girls) from Shahid Beheshti University of Medical Sciences. They were selected using a convenience sampling method. Inclusion criteria were being a student, aged $\geq 18$ years, and voluntary participation in the research.

Exclusion criteria were no history of pharmacotherapy for psychopathy and no history of hospital admission for psychopathy. DCQ was translated into Persian and assessed by several $\mathrm{PhD}$ students in the field of clinical psychology. Then, two English experts were requested to translate it into English. The translated text was compared to the original text and the confounding points were resolved. Next, the questionnaire was implemented on a sample of 20 people and the problems were resolved. The final questionnaire was prepared, accordingly.

\section{Dysmorphic Concern Questionnaire (DCQ)}

The questionnaire contains 7 items that measure concern about physical appearance. The responses are scored based on a 4-point Likert-type scale (0-3); three indicates the most serious concern about dysmorphia. The questionnaire items explore concerns about physical appearance, belief in dysmorphia and deformity, belief in physical tortuosity (e.g. bad smell), and consultation with cosmetic specialists. Although these people are assured about having normal appearance, they refuse to believe it and are preoccupied with concerns about their appearance and correcting their imagined defects. DCQ is a dimensional scale of concern about appearance and has been used in multiple clinical settings (Jorgensen et al., 2001; Kisely, Morkell, Allbrook, Briggs, \& Jovanovic, 2002; Oosthuizen et al., 1998). DCQ scores are strongly correlated with Body Dysmorphic Disorder Examination (BDDE) scores (a reliable and valid scale for BDD) (Rosen \& Reiter, 1996). Although DCQ does not directly measure BDD, it can assess clinical and subclinical concerns about appearance without prejudging the etiology and pathology of the disorder (Jorgensen et al., 2001).

\section{Self-Compassion Scale (Short-Form)}

The questionnaire consists of 12 items. The responses are scored based on a five-point Likert-type scale (1: Almost never; 5: Almost always). The questionnaire includes some items, like "I try to be patient and understand those aspects of my personality that I do not like". The three-component bipolar questionnaire measures 6 subscales of self-compassion, self-judgment (inverse), mindfulness/extreme replication (inverse), and reminiscences/isolation (inverse). The short form is highly correlated with the long-form $(\mathrm{r}=0.97)$ and its reliability is reported as 0.92 (Raes, Pommier, Neff, \& Van Gucht, 2011). 


\section{External Shame Scale}

This is an 18-item self-report tool developed by Goss, Gilbert, \& Allan (1994) for measuring external shame. It is adapted from the Internal Shame Questionnaire (ISQ). Each option includes items, such as "others do not see me at their level", "I think others can understand my flaws". It is scored based on a 5-point Likert-type scale ( $0=$ never, $1=$ rarely, $2=$ sometimes, $3=$ frequently, $4=$ almost always). Respondents are trained to respond to the feelings expressed in each option on a frequency basis. The sum of scores of all questions is calculated to obtain the overall score of external shame. Higher scores indicate high levels of external shame. The reliability of the instrument is high $(\alpha=0.94)$ and its test-retest reliability was calculated as 0.94 in a 5-week interval. This questionnaire is moderately and highly correlated with the negative assessment of fear and other measurements of shame, respectively, in clinical populations and students (Goss, Gilbert, \& Allan, 1994).

\section{Negative Affect Scale (NAS)}

Watson, Clark, \& Tellegen (1988) developed this 20item scale. The short-form NAS consists of 10 items and is scored based on a 5-point scale ( $1=$ very low; $5=$ very high). Its Cronbach's alpha coefficient was calculated as 0.87 and its retest reliability was equal to 0.81 in an 8-week interval. Its correlation with the Beck Depression Inventory was measured as 0.58 and with ApparentHidden Anxiety Inventory, it was equal to 0.51 (Watson, Clark, \& Tellegen, 1988).

\section{Ahwaz Perfectionism Scale}

This is a self-reporting instrument with 27 items (Mohammdi, 2016). It is scored based on a Likert-type scale $(0=$ never, $1=$ rarely, $2=$ sometimes, $3=$ often). The sum of all questions was calculated to obtain the overall score of perfectionism. Higher scores represent high levels of perfectionism. The
Cronbach's alpha coefficient was calculated as 0.89 , and its retest reliability was reported as 0.68 in a 4-week interval. Pearson's correlation coefficient revealed a correlation between the scores of Perfectionism Scale, Cooper Smith's Self-esteem Questionnaire ( $\mathrm{r}=0.39)$, and Somatic Complaint List (SCL-90) (r=0.41) (Mohammdi, 2016).

The sample was selected from Bachelor's, Master's, and PhD students at Shahid Beheshti University of Medical Sciences. They individually completed DCQ, selfcompassion, external shame, negative affect and Ahwaz perfectionism scales. The collected data were also analyzed using Pearson's correlation coefficient, factor analysis, and Independent Samples t-test. The achieved data were analyzed in LISREL and SPSS.

\section{Results}

Two hundred and ten students, aged 18-32 (Mean \pm SD: $22.10 \pm 2.39$ ) years participated in this study. Of these, 131 (62.4\%) were bachelor's students, 53 (25.2\%) were master's students, and 26 (12.4\%) were PhD students. Table 1 presents the gender-wise overall score of DCQ. There was no significant difference in the overall scores of DCQ between males and females $(\mathrm{P}>0.005)$.

In the Exploratory Factor Analysis (EFA), to determine the adequacy of the sample, Bartlett's test of sphericity and the Kaiser-Meyer-Olkin (KMO) test were used. The Bartlett's test of sphericity indicated $X^{2}=351$ and the significance level $=0.001$. The KMO index was 0.82 . These two results indicated adequacy of the sample and appropriate indicators for EFA. One factor was extracted from the entire questionnaire using EFA. In total, $44.19 \%$ of the total variance of dysmorphic concern was explained by this factor (eigenvalue $=3.09$ ).

To confirm the factors extracted from the DCQ, a CFA model was implemented using LISREL. Figure 1 shows

Table 1. Comparing dysmorphic concerns in males and females

\begin{tabular}{cccccc}
\hline Gender & Number & Mean \pm SD & t & df & P \\
\hline Females & 107 & $12.19 \pm 3.15$ & -0.999 & 208 & 0.321 \\
Males & 103 & $11.72 \pm 3.65$ & - & - & - \\
\hline
\end{tabular}

Table 2 . One-factor model fitness indices relevant to the dysmorphic concern

\begin{tabular}{ccccccccc}
\hline CFI & NNFI & NFI & GFI & IFI & RMSEA & $\mathbf{X}^{2}$ & df & X $^{2} /$ df \\
\hline 0.97 & 0.95 & 0.94 & 0.96 & 0.97 & 0.07 & 29.76 & 14 & 2.21 \\
\hline & & & & & & & & \\
\hline
\end{tabular}




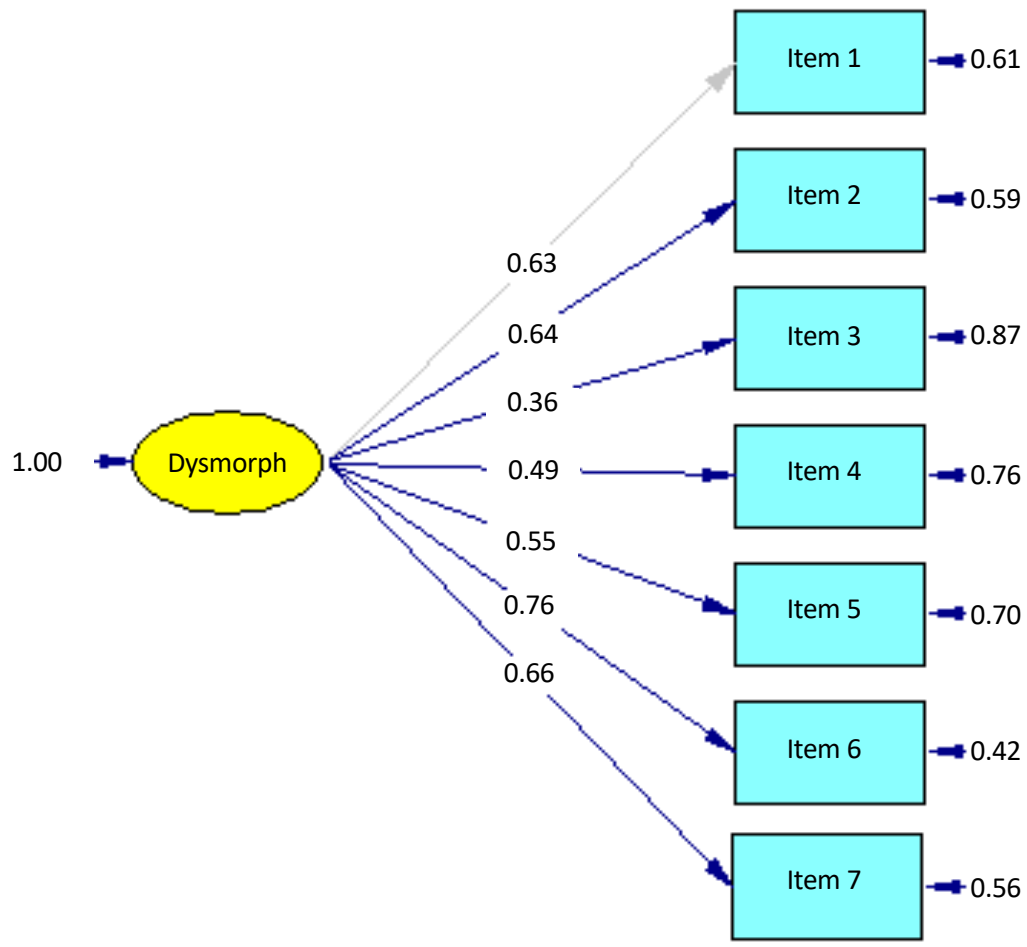

Figure 1. CFA relevant to the dysmorphic concern

the relationship between dysmorphic concerns and the questions. The model fitness indices results are presented in Table 2. The most critical fitting statistic is Chisquared. The statistics suggested the difference between the observed matrix and the estimated matrix. The statistic is sensitive to sample size. Therefore, it is divided by the Degree of Freedom (df) in the larger sample size; $\mathrm{X}^{2}<3$ is acceptable. The contents of the table revealed that $\mathrm{X}^{2}<3$. The fitness is desirable and acceptable if GFI, NFI, and CFI indices are $>0.90$. Therefore, these indices also confirm the fitness of the model.
The self-compassion, external shame, perfectionism, and negative affect scales were used to assess convergent and divergent validity. Pearson's correlation coefficients between the scores of these scales and the DCQ were calculated. The obtained results are presented in Table 3. Contents of Table 3 present that the correlation between the DCQ scores, and the external shame, perfectionism, and negative affect scales is positive and significant. It indicates its high convergence validity. The correlation between DCQ scores and self-compassion scale scores was negative and significant, suggesting high divergent validity.

Table 3. Correlations between dysmorphic concern, self-compassion, external shame, perfectionism, and negative affect

\begin{tabular}{|c|c|c|c|c|c|}
\hline Variable & 1 & 2 & 3 & 4 & 6 \\
\hline Dysmorphic concern & - & -0.16 & $0.38^{*}$ & $0.22 *$ & $0.22^{*}$ \\
\hline Self-compassion & & - & $-0.21^{*}$ & $-0.33^{*}$ & $-0.38^{*}$ \\
\hline External shame & & & - & $0.17^{* *}$ & $0.51^{*}$ \\
\hline Perfectionism & & & & - & $-.44^{*}$ \\
\hline Negative affect & & & & & - \\
\hline
\end{tabular}


The reliability of DCQ was approved using Cronbach's alpha coefficient $(\alpha=0.78)$. The DCQ was retested in 50 students to calculate retest reliability within one week. Then, Pearson's correlation coefficient was calculated between test and re-test scores $(\mathrm{r}=0.92)$, which demonstrated high retest reliability $(\mathrm{P}<0.001)$.

\section{Discussion}

The present study aimed to investigate the psychometric properties of DCQ. The EFA results revealed one factor with more than one eigenvalue. The fitting index of the CFA model confirmed the single-factor model of this questionnaire that explained $44.19 \%$ of the variance of dysmorphic concern $\left(\mathrm{X}^{2} / \mathrm{df} \mathrm{RMSEA}=0.07\right.$, NFI $=0.94$, $\mathrm{CFI}=0.97)$. This result is consistent with those of Avesozine (Oosthuizen et al., 1998), and Jorgensen et al., (2001) confirming a single-factor model of DCQ. The collected results indicated that DCQ has an acceptable validity in the Iranian samples. The study results also suggested the positive and significant relationship of scores of DCQ with the scales of external shame, negative affect, and perfectionism; this finding reflected the concurrent validity of DCQ. These results are consistent with those of Anci and Gurjala (Annesi \& Gorjala, 2010), and Latiumore and Hatjison (Lattimore \& Hutchinson, 2010; Farrell et al., 2005; Taylor \& Cooper, 1992; Phillips, Kim, \& Hudson 1995 ; Ferreira, Pinto-Gouveia, \& Duarte, 2013), as well as Hanstöck and OMahoney (2002). The mentioned authors argued that external shame, negative affect, and perfectionism are positively correlated with body-image dissatisfaction.

The DCQ scores are negatively correlated with selfcompassion scores, suggesting the acceptable divergent validity of the instrument. These results are consistent with those of Ferreira, Pinto-Gouveia, \& Duarte (2013) and Wasylkiw, MacKinnon \& MacKinnon (2012) who documented that self-compassion has a significant and negative relationship with body-image dissatisfaction in the general population. Dysmorphic concerns and body-image dissatisfaction are associated with numerous mental problems and its prevalence is high in the society. Therefore, it is essential to develop a short-form and appropriate instrument for assessing and screening dysmorphic concerns in the Iranian society.

The acquired results suggested that DCQ can be used as a useful tool to measure dysmorphic concern. The internal consistency of this scale's items was assessed by calculating Cronbach's alpha coefficient $(\alpha=0.78)$. The obtained results are consistent with those of Oosthuizen (1998) and Jargensen et al. (2001), indicating the acceptable reliability of this scale. The test-retest reliability of the instrument was equal to 0.92 , which revealed the desirable reliability of the instrument. There was no significant difference between the mean scores of dysmorphic concerns in girls and boys. These results are consistent with those of Talaei, et al., (2009). regarding the Diagnostic and Statistical Manual of Mental Disorders, $5^{\text {th }}$ Edition: DSM-V (Talaei, et al. 2009).

DCQ has acceptable factor structure, validity, reliability, and internal consistency. It can be used as a valid tool in student population. This study also had some limitations. The sample was selected from non-clinical young students that restricted the generalization of the study results to other samples, especially the clinical samples. Therefore, other studies should be conducted on other populations, like individuals with the dysmorphic disorder and undergoing cosmetic surgery.

A limitation of this research was that the community consisted of only educated people that can restrict the generalization of results to other populations. Another limitation of this research was the cultural burden of the meaning of each item that in back-translation to Persian, the meaning of the original version of the questionnaire may not be fully transmitted. However, in this study, experienced experts were used in this field. Therefore, it is suggested that this questionnaire be implemented on non-academic subjects and different groups.

\section{Ethical Considerations}

\section{Compliance with ethical guidelines}

Participation in this study had informed consent, and were willing to respond to the questionnaires. They were assured of the confidentiality of their information.

\section{Funding}

This was a self-funded research project. We received no financial support from any particular organization or institution.

\section{Authors' contributions}

Conceptualization, investigation, data analysis, and draft preparation: Sajad Khanjani; design, data analysis, and writing: Aliakbar Foroughi; Statistical technical support, design, and review: Yousef Asmari.

\section{Conflict of interest}

The authors declared no conflicts of interest. 


\section{References}

Association, A. P. (2013). Diagnostic and statistical manual of mental disorders. BMC Med, 17, 133-7.

Ahamed, S. S., Enani, J., Alfaraidi, L., Sannari, L., Algain, R., \& Alsawah, Z., et al. (2016). Prevalence of body dysmorphic disorder and its association with body features in female medical students. Iranian Journal of Psychiatry and Behavioral Sciences, 10(2), e3868. [DOI:10.17795/ijpbs-3868] [PMID] [PMCID]

Annesi, J. J., \& Gorjala, S. (2010). Body satisfaction and overall mood: Effects of race in exercisers with obesity. Social Behavior and Personality: An International Journal, 38(8), 1105-9. [DOI:10.2224/sbp.2010.38.8.1105]

American Psychiatric Association. (2013). Diagnostic and statistical manual of mental disorders. BMC Medicine, 17, 133-7.

Beilharz, F., Phillipou, A., Castle, D., Jenkins, Z., Cistullo, L., \& Rossell, S. (2019). Dysmorphic concern in anorexia nervosa: Implications for recovery. Psychiatry Research, 273, 657-61. [DOI:10.1016/j.psychres.2019.01.102] [PMID]

Dey, J. K., Ishii, M., Phillis, M., Byrne, P. J., Boahene, K. D., \& Ishii, L. E. (2015). Body dysmorphic disorder in a facial plastic and reconstructive surgery clinic: Measuring prevalence, assessing comorbidities, and validating a feasible screening instrument. JAMA Facial Plastic Surgery, 17(2), 137-43. [DOI:10.1001/jamafacial.2014.1492] [PMID]

Farrell, C., Lee, M., \& Shafran, R. (2005). Assessment of body size estimation: A review. European Eating Disorders Review: The Professional Journal of the Eating Disorders Association, 13(2), 75-88. [DOI:10.1002/erv.622]

Ferreira, C., Pinto-Gouveia, J., \& Duarte, C. (2013). Self-compassion in the face of shame and body image dissatisfaction: Implications for eating disorders. Eating Behaviors, 14(2), 207-10. [DOI:10.1016/j.eatbeh.2013.01.005] [PMID]

Gieler, T., Schmutzer, G., Braehler, E., Schut, C., Peters, E., \& Kupfer, J. (2016). Shadows of beauty - prevalence of body dysmorphic concerns in Germany is increasing: Data from two representative samples from 2002 and 2013. Acta Dermato-Venereologica, 96(217), 83-90. [DOI:10.2340/00015555-2375] [PMID]

Goss, K., Gilbert, P., \& Allan, S. (1994). An exploration of shame measures-I: The other as Shamer scale. Personality and Individual Differences, 17(5), 713-7. [DOI:10.1016/0191-8869(94)90149-X]

Grant, J. E., Lust, K., \& Chamberlain, S. R. (2019). Body dysmorphic disorder and its relationship to sexuality, impulsivity, and addiction. Psychiatry Research, 273, 260-5. [DOI:10.1016/j. psychres.2019.01.036] [PMID] [PMCID]

Hanstock, T. L., \& O'Mahony, J. F. (2002). Perfectionism, acne and appearance concerns. Personality and Individual Differences, 32(8), 1317-25. [DOI:10.1016/S0191-8869(01)00120-9]

Jorgensen, L., Castle, D., Roberts, C., \& Groth-Marnat, G. (2001) A clinical validation of the Dysmorphic Concern Questionnaire. Australian \& New Zealand Journal of Psychiatry, 35(1), 124-8. [DOI:10.1046/j.1440-1614.2001.00860.x] [PMID]

Kazemini, M., Foroughi, A. A., Khanjani, S., \& Mohammdi, A. (2015). [Factor structure and psychometric properties of Persian version of Dysmorphic Concern Questionnaire (Persian)]. Navid No Journal, 18(60), 56-65.
Kisely, S., Morkell, D., Allbrook, B., Briggs, P., \& Jovanovic, J. (2002). Factors associated with dysmorphic concern and psychiatric morbidity in plastic surgery outpatients. Australian and New Zealand Journal of Psychiatry, 36(1), 121-6. [DOI:10.1046/j.1440-1614.2002.00981.x] [PMID]

Kline, R. B. (2015). Principles and practice of structural equation modeling. New York: Guilford Publications.

Koran, L. M., Abujaoude, E., Large, M. D., \& Serpe, R. T. (2008) The prevalence of body dysmorphic disorder in the United States adult population. CNS Spectrums, 13(4), 316-22. [DOI:10.1017/S1092852900016436] [PMID]

Lattimore, P., \& Hutchinson, R. (2010). Perceived calorie intake and state body-image satisfaction in women attempting weight loss: A preliminary investigation. Body Image, 7(1), 1521. [DOI:10.1016/j.bodyim.2009.08.002] [PMID]

Liao, Y., Knoesen, N. P., Deng, Y., Tang, J., Castle, D. J., \& Bookun, R., et al. (2010). Body dysmorphic disorder, social anxiety and depressive symptoms in Chinese medical students. Social Psychiatry and Psychiatric Epidemiology, 45(10), 963-71. [DOI:10.1007/ s00127-009-0139-9] [PMID]

Mancuso, S. G., Knoesen, N. P., \& Castle, D. J. (2010). The Dysmorphic Concern Questionnaire: A screening measure for body dysmorphic disorder. Australian $\mathcal{E}$ New Zealand Journal of Psychiatry, 44(6), 535-42. [DOI:10.3109/00048671003596055] [PMID]

Mohammdi, A. (2016). Factor Structure and Psychometric Properties of Persian Version of Dysmorphic Concern Questionnaire. Navid No, 18(61), 56-65.

Murphy, H. (1973). The detection of psychiatric illness by questionnaire: A technique for the identification and assessment of nonpsychotic psychiatric illness. Canadian Psychiatric Association Journal, 18(4), 348-9. [DOI:10.1177/070674377301800421]

Oosthuizen, P., Lambert, T., \& Castle, D. J. (1998). Dysmorphic concern: Prevalence and associations with clinical variables. Australian and New Zealand Journal of Psychiatry, 32(1), 129-32 [DOI:10.3109/00048679809062719] [PMID]

Phillips, K. A., Grant, J., Siniscalchi, J., \& Albertini, R. S. (2005). Surgical nonpsychiatric medical treatment of patients with body dysmorphic disorder. Focus, 3(2), 304-9. [DOI:10.1176/foc.3.2.304]

Phillips, K. A., Kim, J. M., \& Hudson, J. I. (1995). Body image disturbance in body dysmorphic disorder and eating disorders: Obsessions or delusions? Psychiatric Clinics of North America, 18(2), 317-34. [DOI:10.1016/S0193-953X(18)30057-1]

Phillips, K. A., McElroy, S. L., Keck, P. E. Jr., Pope, H. G., \& Hudson, J. I. (1993). Body dysmorphic disorder: 30 cases of imagined ugliness. American Journal of Psychiatry, 150(2), 302-8. [DOI:10.1176/ ajp.150.2.302] [PMID]

Phillips, K. A., Siniscalchi, J. M., \& McElroy, S. L. (2004). Depression, anxiety, anger, and somatic symptoms in patients with body dysmorphic disorder. Psychiatric Quarterly, 75(4), 309-20. [DOI:10.1023/B:PSAQ.0000043507.03596.0d] [PMID] [PMCID]

Raes, F., Pommier, E., Neff, K. D., \& Van Gucht, D. (2011). Construc tion and factorial validation of a short form of the self-compassion scale. Clinical Psychology \& Psychotherapy, 18(3), 250-5. [DOI:10.1002/cpp.702] [PMID]

Ritter, V., Fluhr, J. W., Schliemann-Willers, S., Elsner, P., Strauß, B., \& Stangier, U. (2016). Body dysmorphic concerns, social adaptation, and motivation for psychotherapeutic support in dermatological 
outpatients. Journal der Deutschen Dermatologischen Gesellschaft, 14(9), 901-8. [DOI:10.1111/ddg.12908]

Rosen, J. C., \& Reiter, J. (1996). Development of the body dysmorphic disorder examination. Behaviour Research and Therapy, 34(9), 75566. [DOI:10.1016/0005-7967(96)00024-1]

Senín-Calderón, C., Valdés-Díaz, M., Benítez-Hernández, M. M., Núñez-Gaitán, M. C., Perona-Garcelán, S., \& Martínez-Cervantes, R., et al. (2017). Validation of Spanish language evaluation instruments for body dysmorphic disorder and the dysmorphic concern construct. Frontiers in Psychology, 8, 1107. [DOI:10.3389/ fpsyg.2017.01107] [PMID] [PMCID]

Singh, A. R., \& Veale, D. (2019). Understanding and treating body dysmorphic disorder. Indian Journal of Psychiatry, 61(Suppl 1), S131-S5. [DOI:10.4103/psychiatry.IndianJPsychiatry_528_18] [PMID] [PMCID]

Stangier, U., Janich, C., Adam-Schwebe, S., Berger, P., \& Wolter, M. (2003). Screening for body dysmorphic disorder in dermatological outpatients. Dermatology and Psychosomatics/Dermatologie und Psychosomatik, 4(2), 66-71. [DOI:10.1159/000072194]

Talaei, A., Fayyazi Bordbar, M. R., Nasiraei, A., \& Rezaei Ardani, A. (2009). [Evaluation of symptom patterns and frequency of body dysmorphic disorder in students of Mashhad University of Medical Sciences (Persian)]. Medical Journal of Mashhad University of Medical Sciences, 52(1), 49-56.

Taylor, M. J., \& Cooper, P. J. (1992). An experimental study of the effect of mood on body size perception. Behaviour Research and Therapy, 30(1), 53-8. [DOI:10.1016/0005-7967(92)90096-Y]

Wasylkiw, L., MacKinnon, A. L., \& MacLellan, A. M. (2012). Exploring the link between self-compassion and body image in university women. Body Image, 9(2), 236-45. [DOI:10.1016/j. bodyim.2012.01.007] [PMID]

Watson, D., Clark, L. A., \& Tellegen, A. (1988). Development and validation of brief measures of positive and negative affect: The PANAS scales. Journal of Personality and Social Psychology, 54(6), 1063-70. [DOI:10.1037/0022-3514.54.6.1063] [PMID] 